\title{
An update on the prevalence of low back pain in Africa: a systematic review and meta-analyses
}

\author{
Linzette Deidrè Morris ${ }^{1,2^{*}}$, Kurt John Daniels ${ }^{1}$, Bhaswati Ganguli ${ }^{3}$ and Quinette Abegail Louw
}

\begin{abstract}
Background: Low back pain (LBP) remains a common health problem and one of the most prevalent musculoskeletal conditions found among developed and developing nations. The following paper reports on an updated search of the current literature into the prevalence of LBP among African nations and highlights the specific challenges faced in retrieving epidemiological information in Africa.

Methods: A comprehensive search of all accessible bibliographic databases was conducted. Population-based studies into the prevalence of LBP among children/adolescents and adults living in Africa were included.

Methodological quality of included studies was appraised using an adapted tool. Meta-analyses, subgroup analyses, sensitivity analyses and publication bias were also conducted.

Results: Sixty-five studies were included in this review. The majority of the studies were conducted in Nigeria $(n=31 ; 47 \%)$ and South Africa $(n=16 ; 25 \%)$. Forty-three included studies $(66.2 \%)$ were found to be of higher methodological quality. The pooled lifetime, annual and point prevalence of LBP in Africa was 47\% (95\% Cl 37;58); 57\% (95\% Cl 51;63) and 39\% (95\% Cl 30;47), respectively.

Conclusion: This review found that the lifetime, annual and point prevalence of LBP among African nations was considerably higher than or comparable to global LBP prevalence estimates reported. Due to the poor methodological quality found among many of the included studies, the over-representation of affluent countries and the difficulty in sourcing and retrieving potential African studies, it is recommended that future African LBP researchers conduct methodologically robust studies and report their findings in accessible resources.
\end{abstract}

Trial registration: The original protocol of this systematic review was initially registered on PROSPERO with registration number CRD42014010417 on 09 July 2014.

Keywords: Low back pain, Africa, Prevalence, Epidemiology, Systematic review, Meta-analysis

\section{Background}

Low back pain (LBP) is arguably the most prevalent musculoskeletal condition found among both developed and developing nations [1-4]. Broadly defined as pain or discomfort in the lumbar region of the spine [1, 2]; LBP is the leading cause of activity limitation, results in significant losses in productivity at work and incurs billions

\footnotetext{
* Correspondence: Idmorris@sun.ac.za

${ }^{1}$ Division of Physiotherapy, Department of Health and Rehabilitation

Sciences, Faculty of Medicine and Health Sciences, Stellenbosch University, PO BOX 241, Cape Town 8000, South Africa

2Division of Epidemiology and Biostatistics, Faculty of Medicine and Health

Sciences, Stellenbosch University, Tygerberg, South Africa

Full list of author information is available at the end of the article
}

of dollars in medical expenditure annually [1, 3, 4]. The prevalence of LBP worldwide is estimated to be between 30 and $80 \%$ among the general population and has been found to increase with age [5]. In addition, a higher prevalence of LBP has been associated with a lower socioeconomic status and lower education levels $[5,6]$. According to the Global Burden of Disease (GBD) 2010 study, LBP is currently the sixth highest burden on a list of 291 conditions and is the cause of more years lived with disability (YLDs) globally than any other disease [4]. Affecting just about anyone, of any gender, race or socioeconomic background [6], LBP has a substantial impact on the overall and financial well-being of an

(c) The Author(s). 2018 Open Access This article is distributed under the terms of the Creative Commons Attribution 4.0 International License (http://creativecommons.org/licenses/by/4.0/), which permits unrestricted use, distribution, and reproduction in any medium, provided you give appropriate credit to the original author(s) and the source, provide a link to the Creative Commons license, and indicate if changes were made. The Creative Commons Public Domain Dedication waiver (http://creativecommons.org/publicdomain/zero/1.0/) applies to the data made available in this article, unless otherwise stated. 
individual and society $[5,7]$. Therefore, it was postulated that the burden of LBP would be greater in lower and middle income countries (LMICs) like those situated in Africa [7, 9]. A systematic review published in 2007 revealed that the prevalence of LBP in Africa was comparable to that of developing nations, and was rising [10].

Despite the GBD 2010 and World Health Organization (WHO) reports $[4,8,9]$, and coupled with the high prevalence of LBP in Africa [10]; LBP and other musculoskeletal conditions remain less prioritized in LMICs, due to more pressing health issues like HIV/AIDS [3]. This is most likely due to the fact that although LBP causes significant disability and related health costs, it is not life-threatening $[4,11]$. LBP however remains a global health concern and an immense burden for LMICs, such as those in Africa where health budgets are already restricted and channelled to other higher priority conditions $[1,2,5,7]$. Of concern is that due to various epidemiologic challenges faced in various LMICs in Africa and the subsequent lack of accurate data, the true burden of LBP is still not well understood or known. In the 7 years since the previous review was published, a large number of studies have emerged. The following paper therefore reports on an updated search of the current literature into the prevalence of LBP among African nations (children, adolescents, adults; males and females). It was hoped that a better understanding of the current burden of LBP in African LMICs would be established. Furthermore, this paper also highlights the specific challenges faced in retrieving epidemiological information in Africa and on conducting meta-analyses of LBP data, as well as the methodological shortcomings of published African studies.

\section{Methods}

The MOOSE (Meta-analysis Of Observational Studies in Epidemiology) were used [12]. The protocol for this updated review was registered on PROSPERO prior to commencement (protocol registration number: CRD42014010417) [13].

Studies had to primarily report on the prevalence of LBP among nations situated on the African continent were included. Studies could report on the prevalence of musculoskeletal conditions as a whole, yet had to provide subgroup data for LBP prevalence. Studies could report on the following recall periods for LBP prevalence, namely: point, annual or lifetime prevalence. Subjects included in the studies could be any race, gender and age. Studies could be published in English, Afrikaans or French, since these are three of the most common languages in which scholarly communication in Africa is conducted [14]. French studies were translated by a French-speaking African native. To validate the translations, we cross-checked the French translations with the English abstract of the article (which is typically available online) to check for any marked discrepancies and reverse translations were done to ensure validity of translations. Dissertations, conference proceedings, commentaries/letters and other grey literature were excluded from this review.

A comprehensive update of the previous search [10] was conducted in the following bibliographic databases via the Stellenbosch University's library website: EbscoHost (including CiNAHL, Africa-Wide Information, Health Source: Nursing/Academic edition, SPORTDiscus) , Medline, ScienceDirect, Scopus, PEDro, PubMed, SA ePublications, Cochrane Library, ProQuest Medical Library, African Journals Online (AJOL) and Web of Science. The main search terms were: low back pain, Africa and prevalence. The original search strategy was revised where necessary and excluded management and rehabilitation. The full search strategy is available on request from the corresponding author. Secondary searching (PEARLing) was conducted (PEARLing is a search method whereby the reference lists of all included and excluded studies are searched for other studies which may not have been identified during the database search). Manual searching was not conducted due to the difficulty in replicating this method. The search was commenced and conducted between June 2014 and October 2014, and an updated search was conducted in March 2015 and July 2016. A final search was conducted in April 2017, prior to submission. Articles published and indexed from inception of the databases to the end of the search period were included.

The titles and abstracts of all potentially relevant population-based studies were screened by two reviewers independently. Methodological appraisal of included studies was conducted using the same critical appraisal tool as in the original review [10, 15]. The tool was however further adapted for use in this review (Table 1), by reducing the previous items 7,8 and 9 to one item $(7 a-c)$, as all these items pertained to the validation of the data collection tool used in the study. For the purposes of this review, all items in the appraisal tool were equally weighed and the total score for the tool was 10. No subminimum criteria were applied.

Appraisal of studies was conducted independently by two reviewers. Studies scoring $60 \%$ or less on the appraisal tool were deemed as low quality studies and were excluded from the meta-analyses. The $60 \%$ cut-off was deemed appropriate based on the fact that no subminimum criteria were applied due to the heterogeneous nature of LBP data and that the average methodological score of all studies was $66 \%$. It was therefore decided that all studies which were below the average score were relatively lower in methodological quality compared to the rest of the included studies. 
Table 1 Methodological appraisal tool for LBP prevalence studies (adapted) [15]

\begin{tabular}{|c|c|c|}
\hline Criteria & Yes/No & Comments \\
\hline \multicolumn{3}{|c|}{ Is the final sample representative of the target population? } \\
\hline \multicolumn{3}{|l|}{$\begin{array}{l}\text { 1. At least } 1 \text { of the following must apply } \\
\text { in the study: an entire target } \\
\text { population, randomly selected sample } \\
\text { or sample stated to represent the } \\
\text { target population. }\end{array}$} \\
\hline \multicolumn{3}{|l|}{$\begin{array}{l}\text { 2. At least } 1 \text { of the following: reasons for } \\
\text { non-response described, non-responders } \\
\text { described, comparison of responders } \\
\text { and non-responders, or comparison of } \\
\text { sample and target population. }\end{array}$} \\
\hline \multicolumn{3}{|l|}{$\begin{array}{l}\text { 3. Response rate, and if applicable, } \\
\text { drop-out rate reported }\end{array}$} \\
\hline \multicolumn{3}{|l|}{ Quality of data } \\
\hline \multicolumn{3}{|l|}{$\begin{array}{l}\text { 4. Were the data primary data of LBP, or } \\
\text { was it taken from a survey not } \\
\text { specifically designed for that purpose? }\end{array}$} \\
\hline \multicolumn{3}{|l|}{$\begin{array}{l}\text { 5. Were the data collected from each } \\
\text { subject directly or were they collected } \\
\text { from a proxy? }\end{array}$} \\
\hline \multicolumn{3}{|l|}{$\begin{array}{l}\text { 6. Was the same mode of data collection } \\
\text { used for all subjects? }\end{array}$} \\
\hline \multicolumn{3}{|l|}{$\begin{array}{l}\text { 7. At least } 1 \text { of the following in case of: } \\
\text { a) Questionnaire: a validated } \\
\text { questionnaire or at least tested for } \\
\text { reproducibility? } \\
\text { b) Interview: interview validated, tested } \\
\text { for reproducibility, or adequately } \\
\text { described and standardized? } \\
\text { c) Examination: examination validated, } \\
\text { tested for reproducibility, adequately } \\
\text { described and standardized? }\end{array}$} \\
\hline \multicolumn{3}{|l|}{ Definition of LBP } \\
\hline \multicolumn{3}{|l|}{$\begin{array}{l}\text { 8. Was there a precise anatomic } \\
\text { delineation of the lumbar area or } \\
\text { reference to an easily obtainable article } \\
\text { that contains such specification? }\end{array}$} \\
\hline \multicolumn{3}{|l|}{$\begin{array}{l}\text { 9. Was there further useful specification of } \\
\text { the definition of LBP, or question(s) put } \\
\text { to study subjects quoted such as } \\
\text { frequency, duration, or intensity, and } \\
\text { character of the pain. Or was there } \\
\text { reference to an easily obtainable article } \\
\text { that contains such specification? }\end{array}$} \\
\hline \multicolumn{3}{|l|}{$\begin{array}{l}\text { 10. Were the recall periods clearly stated: } \\
\text { e.g. } 1 \text { week, } 1 \text { month, lifetime? }\end{array}$} \\
\hline Total score (10) & & \\
\hline
\end{tabular}

Data were extracted using specifically-designed extraction sheets and were entered into Microsoft (MS) Excel spreadsheets [16]. The following data were extracted from included studies: author name(s), year of publication, country of publication, study design, data collection tool/ outcome measure tool(s), population, study setting (including if rural or urban setting), sample size, age group/age (range and/or mean \pm standard deviation), gender, data collection period, LBP definition, $L B P$ recall period, reliability/validity of measurement tools, response rates and $L B P$ prevalence rates (point, annual and lifetime).

From the data extracted, the pooled point, annual and lifetime prevalence (summary estimates) of LBP among African nations, as well as the $95 \%$ confidence intervals (CI), were calculated for conducting meta-analyses of observational data. A random effects model to adjust for heterogeneity was used since LBP data inherently varies between studies due to differences in risk factors and characteristics between populations. Sub-group analyses were conducted for age group (adults and children/adolescents), country status (low income, low middle income and upper middle income), gender (male and female) and setting (community, industry, hospital, professional and school). Sensitivity analyses were conducted to assess if the inclusion of the lower methodological quality studies would change the results of the analyses. Publication bias was also assessed using Duval and Tweedie's Trim and Fill method [81].

\section{Results}

The results of the comprehensive updated search of literature into the prevalence of LBP in Africa are depicted in Fig. 1. A total of 65 studies were included in this review (of which 40 were published after the original review was conducted) $[17-70,81-91]$. A list of the excluded studies and the reasons for their exclusion is available from the corresponding author.

\section{General description of included studies}

More than $72.3 \%$ of the included studies were conducted in lower income and lower middle income countries $[17,21,22,25-29,31-34,36,37,40-44$, $46-48,50-53,57-60,63-67,69,83-91]$. The majority of the studies were conducted in Nigeria, which is a lower middle income country $(n=31 ; 47.7 \%)[22,25,27,29,32$, $33,36,41,44,46-48,50,52,53,57-60,64-66,81-83$, 86-91] and South Africa, which is an upper middle income country $(n=16 ; 24.6 \%)[19,20,23,24,30,35,38$, $39,45,49,54-56,61,62,70]$. Three of the included studies were published in the French language $[18,26,51]$, the rest were published in English. Fifteen (27.8\%) of the 54 independent African countries (countries as recognised by the United Nations) are represented in this review. Fortyfive studies included both male and female participants (75\%) [17, 18, 20-22, 27-37, 40, 46, 48-53, 55, 57-59, 61, $62,67-70,81,82,84-86,89,90]$. Fourteen of the included studies included children and/or adolescents between the ages 11 and 19 years (21.5\%) [17-19, 31, 34, 35, 41, 44, 53, $56,59,67,69,85]$. The response rates were reported by 72 . $3 \%$ of the studies $(n=47)[19-25,27,28,30-41,46-50$, $52-54,59,61-64,66-70,82,85-91]$ and ranged from 11 to $100 \%$. Forty-two of the studies were conducted in an urban setting (64.6\%), while nine studies (13.8\%) where 


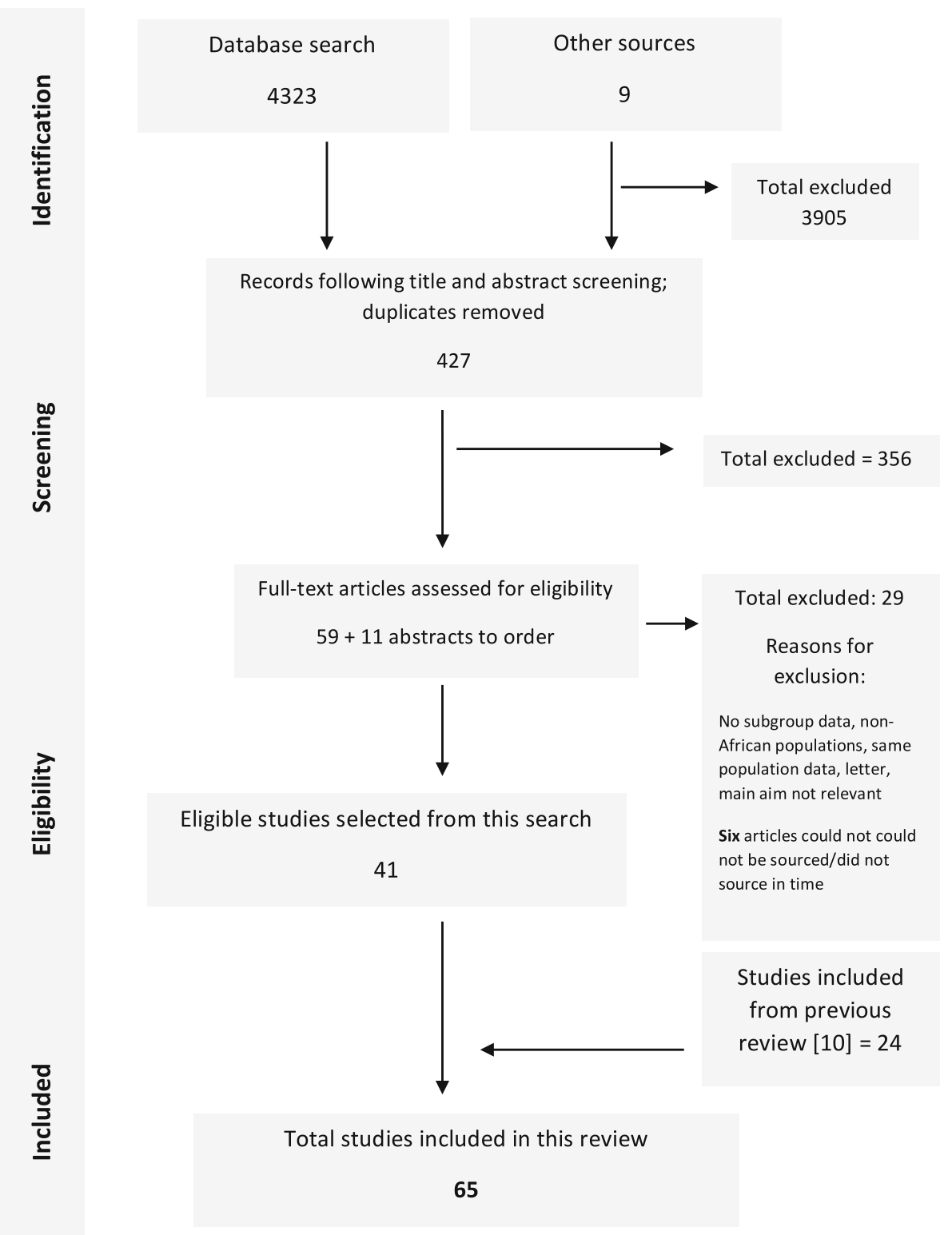

Fig. 1 Flow chart depicting study selection procedure

conducted in a rural setting. The rest of the studies $(n=14$; $21.5 \%)$ were conducted in a setting which incorporated both rural and urban communities.

The most common study design was cross-sectional $(n=60 ; 92.3 \%)$. Two studies used a prospective study design $[17,42]$ and three used a retrospective study design $[21,26,84]$. Most of the included studies used questionnaires. Three studies reviewed medical records [21, 26, $84]$, and eight studies included a physical examination [17, 40, 42-45, 47, 58]. Twelve studies conducted interviews $[17,20,40-44,54,55,57,58,60]$. It was unclear in three of the studies which sampling method was used [19, 50, 59]. Nine studies did not explicitly provide a clear recall period (point, lifetime or annual) for LBP $(15 \%)$ [17, 41,
42, 44, 45, 49, 70, 71, 84]. Two studies used the index pregnancy (up to 40 weeks) as the recall period [60, 83].

The most common population studied was health professionals and hospital staff $(n=17 ; 26.2 \%)[22,28,30,37$, $45,46,48-52,55,61-63,82,91]$. Health professions studies included physiotherapists, general surgeons, dentists, nurses, general surgeons and oral hygienists. Workers were studied in 21 of the eligible studies (32.3\%) $[20,24,26,27,32,33,36,38,39,43,44,47,54,57,64-66$, 81, 87-90] and included the following sectors: commercial, industry, transport and farming. Computer-users were only studied in one included study [36] and two studies included sports players $[19,56]$. The sports players studied were cricketers. One study reported on LBP 
prevalence among school teachers [68]. An overview summary of the descriptive data extracted from the included studies is provided in Table 2.

\section{Methodological quality of included studies}

Twenty-two (33.8\%) of the included studies scored $60 \%$ or less on the specified critical appraisal tool and were therefore excluded from further analysis $[17,19,21,23$, 26, 36, 38, 42, 44-46, 49-51, 55, 56, 58, 64, 83, 84, 86, 90]. Sixty-five percent $(n=42)$ of the included studies reported on the validity and/or reliability of their data collection tools (questionnaire, interview or examination) [31, 32, 34, $35,39,41-48,50,52-70,81,83,85-91]$. Only 24 of the included studies $(36.9 \%)$ provided a case definition for LBP $[18,24,25,30-32,34,35,37,40,41,48,52,57$, $65-69,81,83-85,91]$. Table 3 illustrates the methodological appraisal of the included studies.

\section{Lifetime, annual and point prevalence of LBP among African nations}

Lifetime, annual and point prevalence data of LBP among African nations were calculated to provide a summary estimate. Lifetime prevalence pertains to the experience of LBP at any point in the individual's lifetime; annual prevalence pertains to the experience of LBP at any point in the past 6-12 months; and point prevalence pertains to the experience of LBP at the time of the study's data collection. For these purposes, only African studies reporting a recall period of lifetime, annual or point prevalence for LBP, were included for analyses.

\section{- Lifetime prevalence of LBP in Africa}

Sixteen studies reported on the lifetime prevalence of LBP in Africa [18, 26, 30, 31, 34, 35, 37, 39, 64, 67, 70, 85, 86, 91]. The lifetime prevalence for LBP in Africa was estimated at $47 \%$ (95\% CI 37;58). The summary analyses for lifetime prevalence of LBP among Africans is depicted in Fig. 2.

Sensitivity and subgroup analyses were conducted to ensure that the exclusion of the poorer methodological quality studies would not have influenced the results significantly if included. Figure 3 illustrates the sensitivity and subgroup analyses conducted for lifetime LBP prevalence among Africans. A significant difference between the summary estimates calculated with only the higher quality studies or only the lower quality studies, compared to all studies (combined) was found.

\section{- Annual prevalence of LBP in Africa}

Thirty-four studies reported on the annual prevalence of LBP in Africa [22, 25, 27-29, 32-34, 37, 39, 43, 46-54, 56, $57,59,61,62,65,66,68,81,82,85-89]$. The annual prevalence of LBP in Africa was estimated at $57 \%$ (95\% CI 51;63).
The summary analyses for annual prevalence of LBP among Africans is depicted in Fig. 4.

Figure 5 illustrates the sensitivity and subgroup analyses for annual LBP prevalence among African nations. No significant differences between the summary estimates calculated with only the higher quality studies or only the lower quality studies, compared to all studies (combined) were found.

\section{- Point prevalence of LBP in Africa}

Twenty-three studies reported on point prevalence of LBP in Africa [17, 19-21, 23, 33, 39-42, 45, 54, 55, 58, 59, $63,67,69,84-86,91]$. The point prevalence of LBP in Africa was estimated at $39 \%(95 \%$ CI $30 ; 47)$. The summary analyses for point prevalence of LBP among Africans is depicted in Fig. 6.

Figure 7 illustrates the subgroup and sensitivity analyses for point LBP prevalence among Africans. No significant differences between the summary estimates calculated with only the higher quality studies or only the lower quality studies, compared to all studies (combined) were found.

\section{Publication bias}

Duval and Tweedie's “Trim and Fill” method was used to assess publication bias [80]. Under the random effects model the point estimate and $95 \%$ confidence interval for the combined studies is 0.49 (95\% CI 0.39, 0.57). Using Trim and Fill the imputed point estimate is 0.31 (95\% CI 0.24, 0.39). The method suggests that a total of 13 studies may be missing from this review.

\section{Discussion}

This paper provides an updated synthesis of the literature into the prevalence of LBP among African populations. The current review indicates that although a number of years have passed after our initial review [10], LBP remains a health concern in Africa.

Meta-analyses of the observational data collected from the eligible studies provides a summary estimate of the lifetime, annual and point prevalence. Lifetime, annual and point prevalence of LBP among African populations was found to be higher than recently reported estimates for global LBP prevalence [2, 4, 5]. The global prevalence of LBP reported by Hoy et al. in 2012 was calculated from a total of 165 studies conducted in 54 countries around the globe (developed and developing countries), over a period of 29 years [2]. In our review, the point prevalence of LBP among Africans was estimated at 39\% (95\% CI 30;47), which is considerably higher than the global LBP prevalence estimate (18.3\%) reported by Hoy et al. [2]. Similarly, the annual prevalence for LBP among Africans (57\%; 95\% CI 51;63) found in our review was substantially higher than the global annual LBP 
날

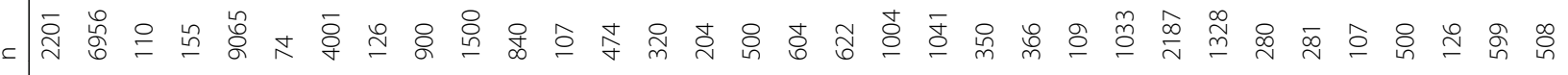

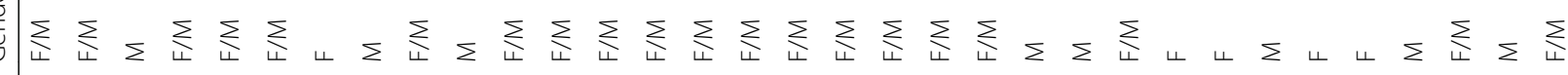

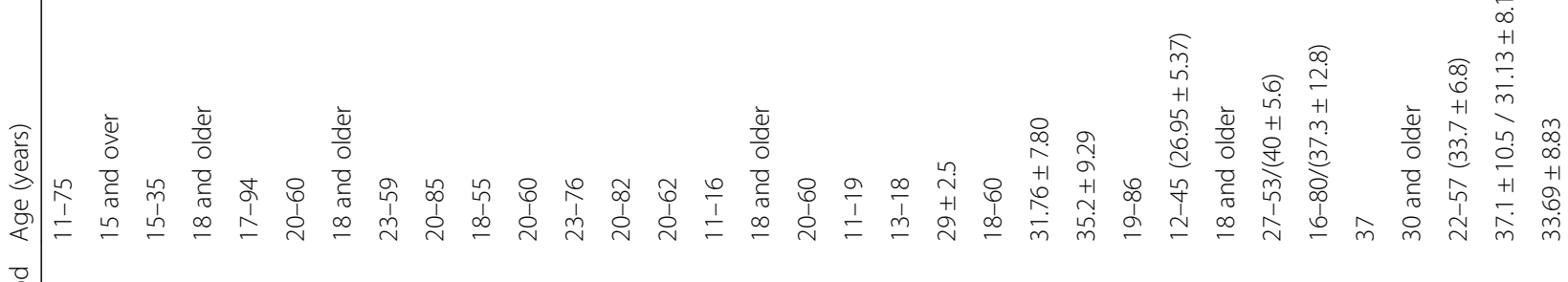

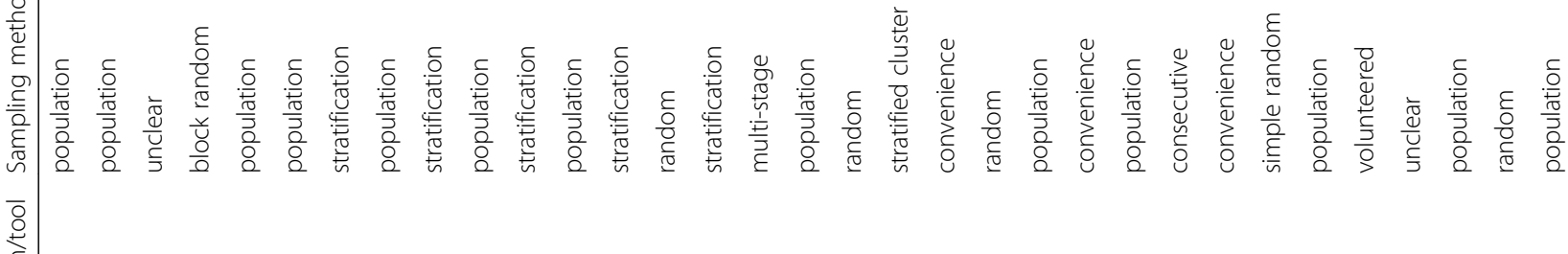

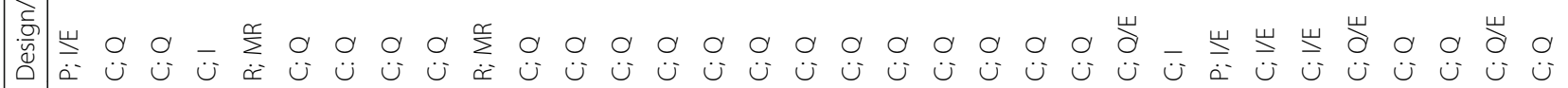

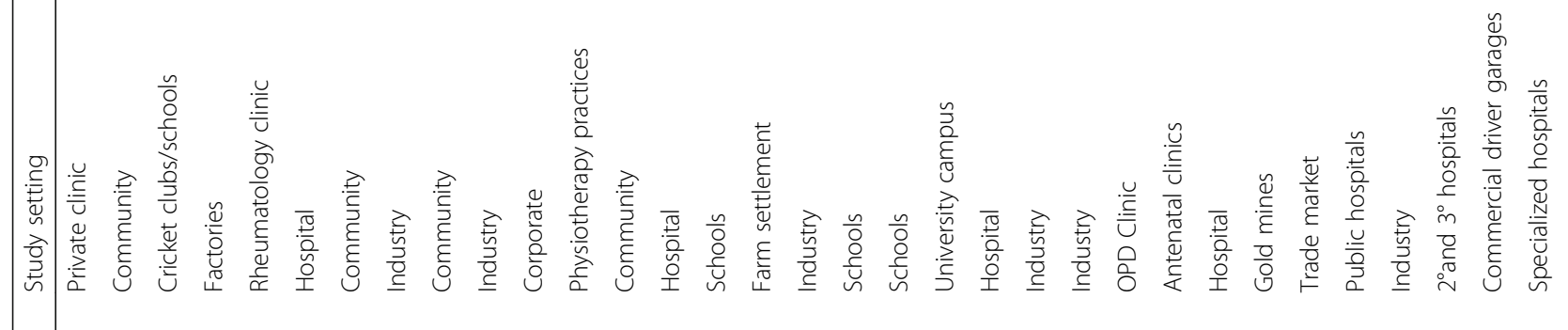

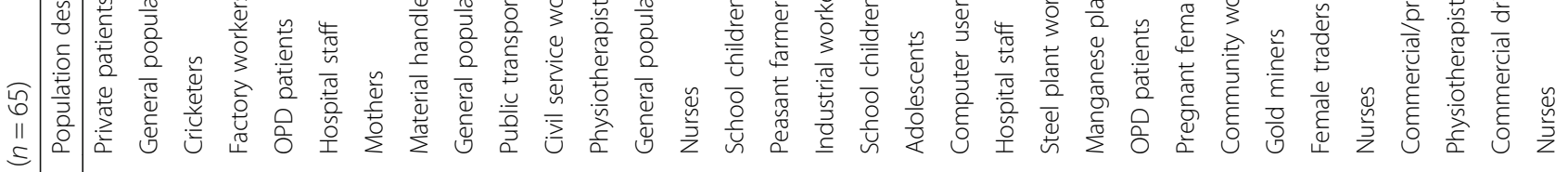

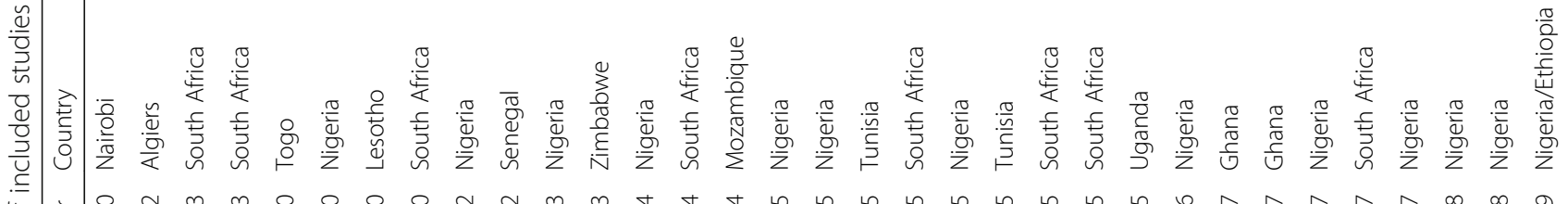

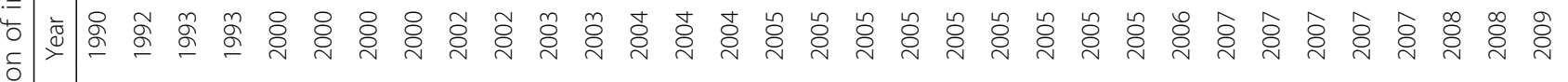

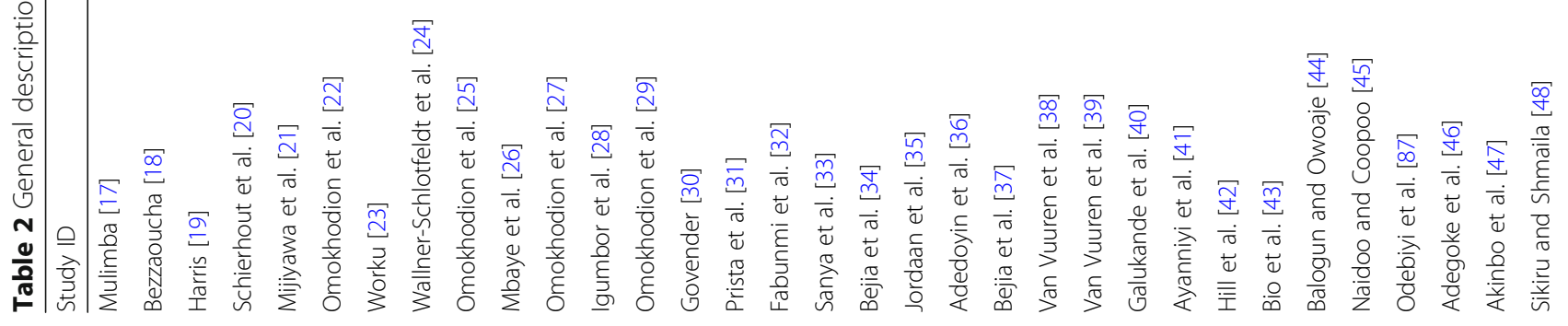




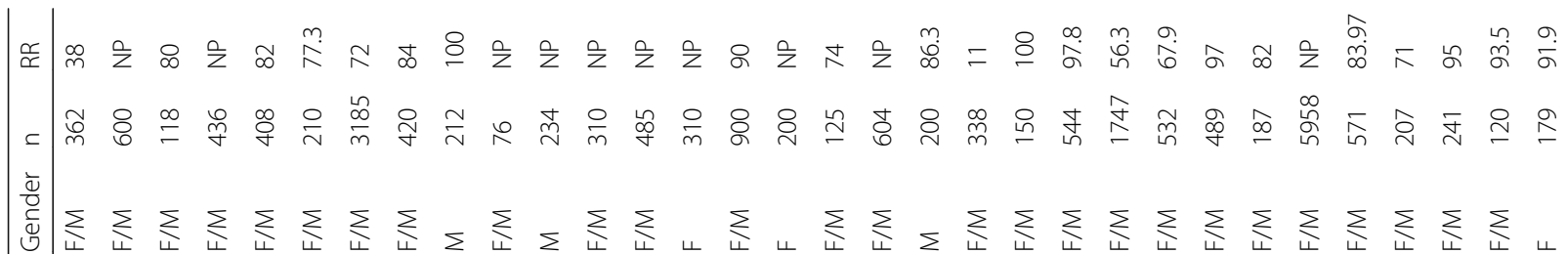

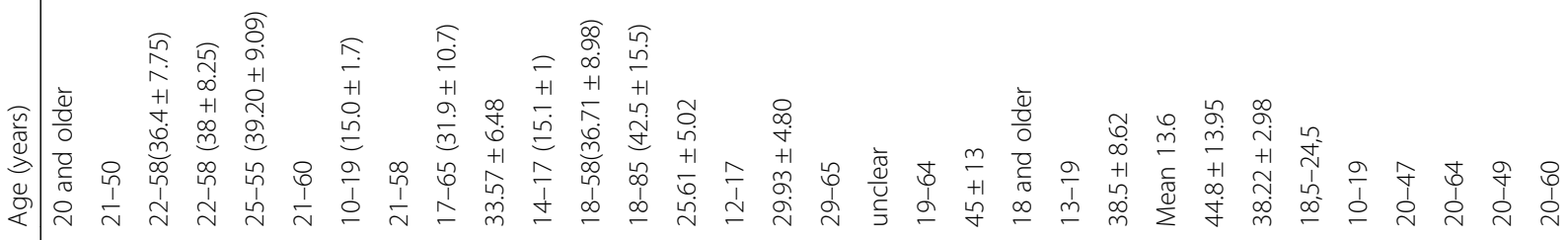

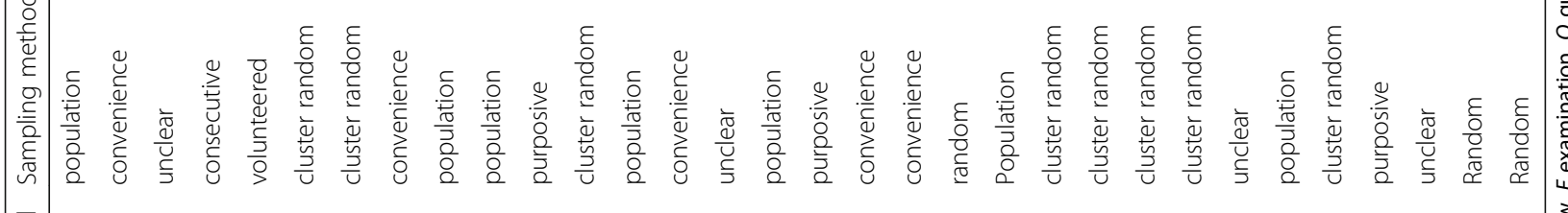

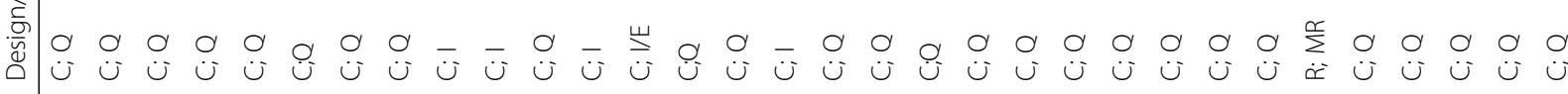

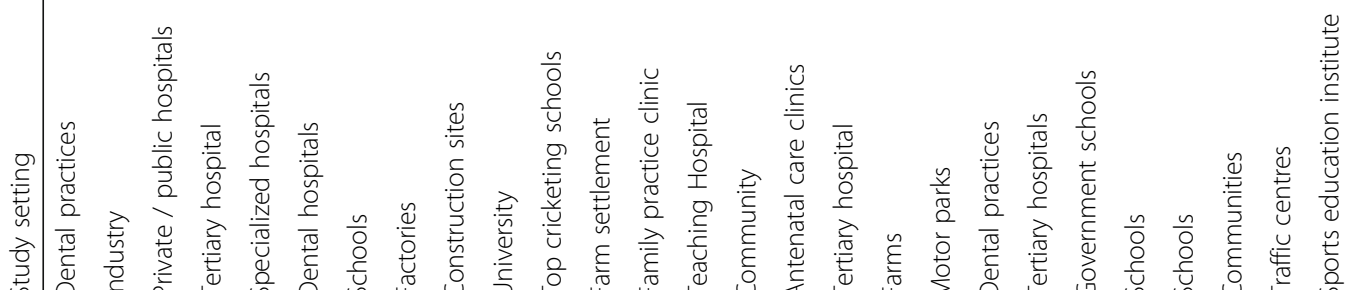



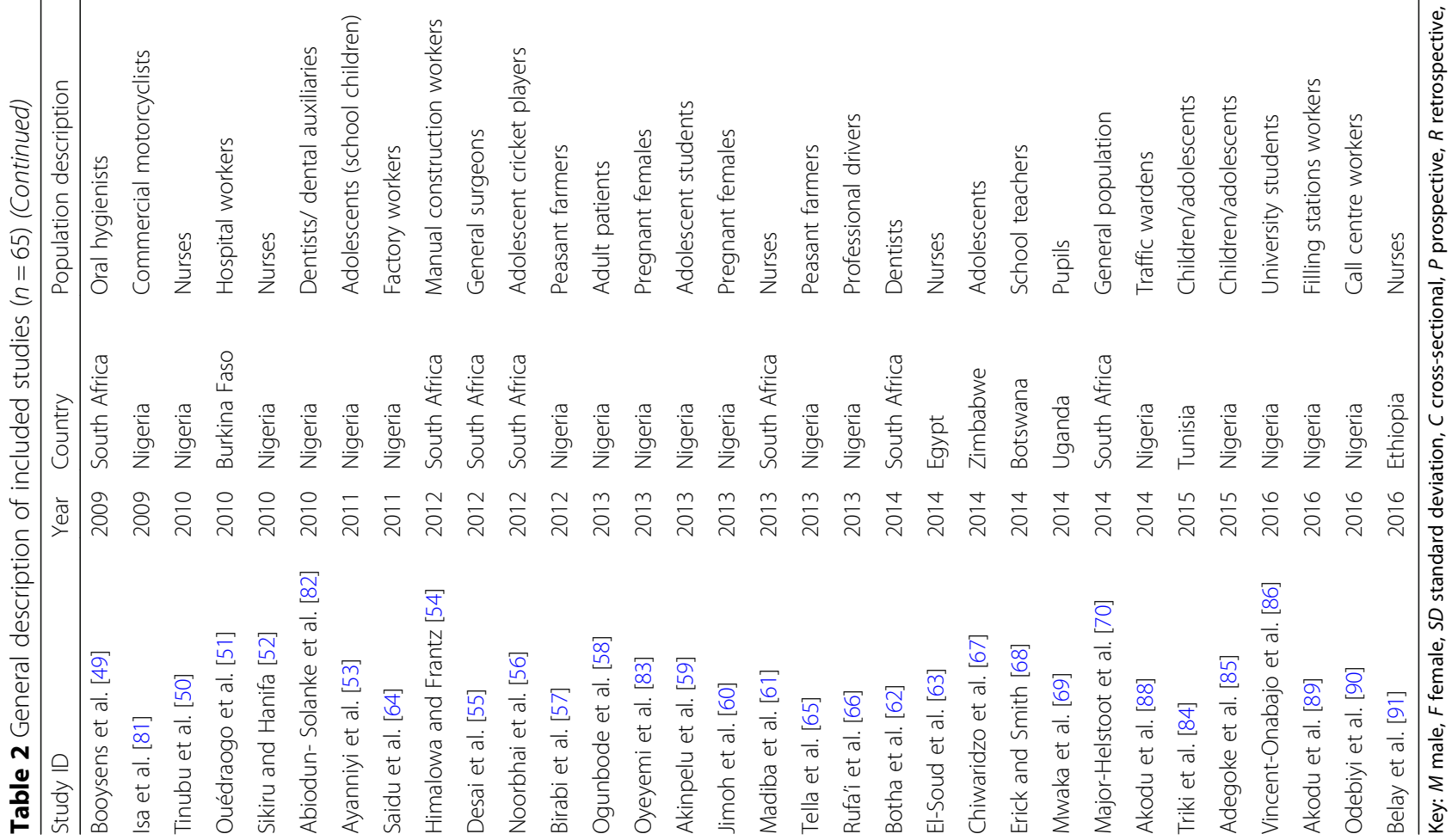


Table 3 Methodological appraisal of included studies $(n=65)$

\begin{tabular}{|c|c|c|c|c|c|c|c|c|c|c|c|c|}
\hline Criterion study ID & 1 & 2 & 3 & 4 & 5 & 6 & 7 & 8 & 9 & 10 & $\%$ & MA \\
\hline Mulimba [17] & + & - & - & + & + & + & - & - & - & - & 40 & No \\
\hline Bezzaoucha [18] & + & - & + & + & + & + & - & + & - & + & 70 & Yes \\
\hline Harris [19] & - & - & + & + & + & + & - & - & + & + & 60 & No \\
\hline Schierhout et al. [20] & + & + & + & + & + & + & - & - & - & + & 70 & Yes \\
\hline Mijiyawa et al. [21] & - & - & - & + & - & + & - & - & - & + & 30 & No \\
\hline Omokhodion et al. [22] & + & - & + & + & + & + & - & - & + & + & 70 & Yes \\
\hline Worku [23] & + & - & + & + & - & + & - & - & + & + & 60 & No \\
\hline Wallner-Schlotfeldt et al. [24] & - & + & + & + & + & + & - & + & + & + & 80 & Yes \\
\hline Omokhodion et al. [25] & + & + & + & + & + & + & - & + & + & + & 90 & Yes \\
\hline Mbaye et al. [26] & - & - & + & + & + & + & - & - & + & + & 60 & No \\
\hline Omokhodion et al. [27] & + & + & + & + & + & + & - & - & - & + & 70 & Yes \\
\hline Igumbor et al. [28] & + & + & + & + & + & + & - & - & + & + & 80 & Yes \\
\hline Omokhodion et al. [29] & + & + & + & + & + & + & - & - & + & + & 80 & Yes \\
\hline Govender [30] & + & + & + & + & + & + & - & + & + & + & 90 & Yes \\
\hline Prista et al. [31] & + & - & + & + & + & + & + & + & + & + & 90 & Yes \\
\hline Fabunmi et al. [32] & + & - & - & + & + & + & + & + & + & + & 80 & Yes \\
\hline Sanya et al. [33] & + & - & + & + & + & + & - & - & + & + & 70 & Yes \\
\hline Bejia et al. [34] & + & + & + & + & + & + & + & + & + & + & 100 & Yes \\
\hline Jordaan et al. [35] & + & + & + & + & + & + & + & + & + & + & 100 & Yes \\
\hline Adedoyin et al. [36] & - & + & + & - & + & + & - & - & + & + & 60 & No \\
\hline Bejia et al. [37] & + & + & + & + & + & + & - & + & + & + & 90 & Yes \\
\hline Van Vuuren et al. [38] & - & - & + & + & + & + & - & - & + & + & 60 & No \\
\hline Van Vuuren et al. [39] & + & + & + & + & + & + & + & - & + & + & 90 & Yes \\
\hline Galukande et al. [40] & - & + & + & + & + & + & - & + & + & + & 80 & Yes \\
\hline Ayanniyi et al. [41] & + & + & + & - & + & + & + & + & + & - & 80 & Yes \\
\hline Hill et al. [42] & + & + & - & - & + & + & + & - & - & - & 50 & No \\
\hline Bio et al. [43] & + & + & - & + & + & + & + & - & + & + & 80 & Yes \\
\hline Balogun and Owoaje [44] & + & - & - & - & + & + & + & - & - & - & 40 & No \\
\hline Naidoo and Coopoo [45] & - & + & + & + & + & + & + & - & - & - & 60 & No \\
\hline Odebiyi et al. [87] & - & - & + & + & + & + & + & - & + & + & 70 & Yes \\
\hline Adegoke et al. [46] & + & - & + & - & + & + & + & - & - & + & 50 & No \\
\hline Akinbo et al. [47] & + & + & - & - & + & + & + & - & + & + & 70 & Yes \\
\hline Sikiru and Shmaila [48] & + & - & + & + & + & + & + & + & + & + & 90 & Yes \\
\hline Booysens et al. [49] & + & - & + & - & + & + & - & - & + & - & 50 & No \\
\hline Isa et al. [82] & + & - & - & + & - & + & + & + & + & + & 70 & Yes \\
\hline Tinubu et al. [50] & - & - & + & - & + & + & + & - & - & + & 50 & No \\
\hline Ouédraogo et al. [51] & - & - & - & + & + & + & - & - & - & + & 40 & No \\
\hline Sikiru and Hanifa [52] & - & - & - & + & + & + & + & + & + & + & 70 & Yes \\
\hline Abiodun-Solanke et al. [83] & + & + & - & - & + & + & - & - & + & + & 60 & Yes \\
\hline Ayanniyi et al. [53] & + & - & + & - & + & + & + & - & + & + & 70 & Yes \\
\hline Saidu et al. [64] & - & - & + & - & + & + & + & - & + & - & 50 & No \\
\hline Himalowa and Frantz [54] & + & + & + & + & + & + & + & - & - & + & 80 & Yes \\
\hline Desai et al. [55] & - & - & - & - & + & + & + & - & + & + & 50 & No \\
\hline Noorbhai et al. [56] & + & - & - & - & + & + & + & - & + & + & 60 & No \\
\hline
\end{tabular}


Table 3 Methodological appraisal of included studies $(n=65)$ (Continued)

\begin{tabular}{|c|c|c|c|c|c|c|c|c|c|c|c|c|}
\hline Criterion study ID & 1 & 2 & 3 & 4 & 5 & 6 & 7 & 8 & 9 & 10 & $\%$ & $M A$ \\
\hline Birabi et al. [57] & + & - & - & + & + & + & + & + & + & + & 80 & Yes \\
\hline Ogunbode et al. [58] & + & - & - & + & + & + & + & - & - & + & 60 & No \\
\hline Oyeyemi et al. [84] & - & - & - & - & + & + & + & + & + & + & 60 & Yes \\
\hline Akinpelu et al. [59] & - & - & + & + & + & + & + & - & + & + & 70 & Yes \\
\hline Jimoh et al. [60] & + & + & - & + & + & + & + & - & + & + & 80 & Yes \\
\hline Madiba et al. [61] & + & - & + & - & + & + & + & - & + & + & 70 & Yes \\
\hline Tella et al. [65] & - & - & - & + & + & + & + & + & + & + & 70 & Yes \\
\hline Rufa'i et al. [66] & - & + & + & + & + & + & + & + & - & + & 80 & Yes \\
\hline Botha et al. [62] & + & - & + & - & + & + & + & - & + & + & 70 & Yes \\
\hline El-Soud et al. [63] & + & + & + & + & + & + & + & - & + & - & 80 & Yes \\
\hline Chiwaridzo et al. [67] & + & + & + & + & + & + & + & + & + & + & 100 & Yes \\
\hline Erick and Smith [68] & + & + & + & + & + & + & + & + & + & + & 100 & Yes \\
\hline Mwaka et al. [69] & + & - & + & - & + & + & + & + & + & - & 70 & Yes \\
\hline Major-Helstoot et al. [70] & + & + & + & + & + & + & + & - & - & + & 80 & Yes \\
\hline Akodu et al. [88] & - & - & + & + & + & + & + & - & + & + & 70 & Yes \\
\hline Triki et al. [84] & + & - & - & + & + & + & - & + & - & - & 50 & No \\
\hline Adegoke et al. [85] & + & - & + & + & + & + & + & + & + & + & 90 & Yes \\
\hline Vincent-Onabajo et al. [86] & - & - & + & + & + & + & + & - & - & + & 60 & Yes \\
\hline Akodu et al. [89] & - & - & + & + & + & + & + & - & + & + & 70 & Yes \\
\hline Odebiyi et al. [90] & + & - & + & - & + & + & + & - & - & + & 60 & Yes \\
\hline Belay et al. [91] & + & - & + & + & + & + & + & + & + & + & 90 & Yes \\
\hline
\end{tabular}

Key: + criteria fulfilled; - criteria not fulfilled; MA Methodologically acceptable

prevalence (38.5\%) reported by Hoy et al. [2]. The lifetime prevalence for LBP among Africans (47\%; 95\% CI 37;58) was also found to be considerably higher than the estimates (38.9\%) reported by Hoy et al. [2]. The summary estimates found in this review were compared specifically to North American and Western European countries. It was found that the point LBP prevalence among Africans was substantially higher than estimates provided for Canada (28.7\%), Denmark (12-13.7\%) and Sweden (23.2\%), and was comparable to Germany (39.2) and Belgium (33\%) [5]. One year LBP prevalence among Africans was considerably higher than Spain (20\%), and on par with Denmark (56\%) and Ukraine (50.3\%) [5]. The findings of this review therefore reiterates the fact that LBP is a burden and is therefore a public health concern among developing nations in Africa [4, 7, 8]. Despite the high burden, LBP remains a lower priority compared to epidemics such as HIV/AIDS in Africa [3]. African healthcare budgets and systems may be generally ill-prepared to deal with the management of LBP which could partly explain the high LBP prevalence among African populations $[4,9,10,71]$. The successful development and implementation of strategies and policies to address the burden of LBP in poorer countries or countries with emerging economies, like those in Africa, is therefore warranted [9].

The lifetime, annual and point prevalence of LBP was estimated to be higher among African adults compared to African children and adolescents. This finding confirms that similarly to developed nations, the prevalence of LBP among Africans increases with age $[1,2,6]$. These summary estimates for annual and lifetime LBP prevalence among African children and adolescents were however found to be higher than estimates reported for the United Kingdom (15.6-24\%), Finland (9.7\%), and Iran (15\%), and comparable to Iceland (34\%) and Denmark (32.4\%) [5], although point prevalence was found to be lower or on par (11\%). Of concern is that the early onset of LBP in childhood or adolescents is a risk factor for developing chronic LBP later in life [53, 72], and once the younger generation become the working class, the ongoing pain and related disability will ultimately affect work productivity and the economy of a country [1, 3, 53]. Therefore, in developing countries or countries with emerging economies like African countries, where budgets are already stringent [10], it would make sense to implement effective prevention strategies to the risk of developing LBP in childhood and/or adolescence, 


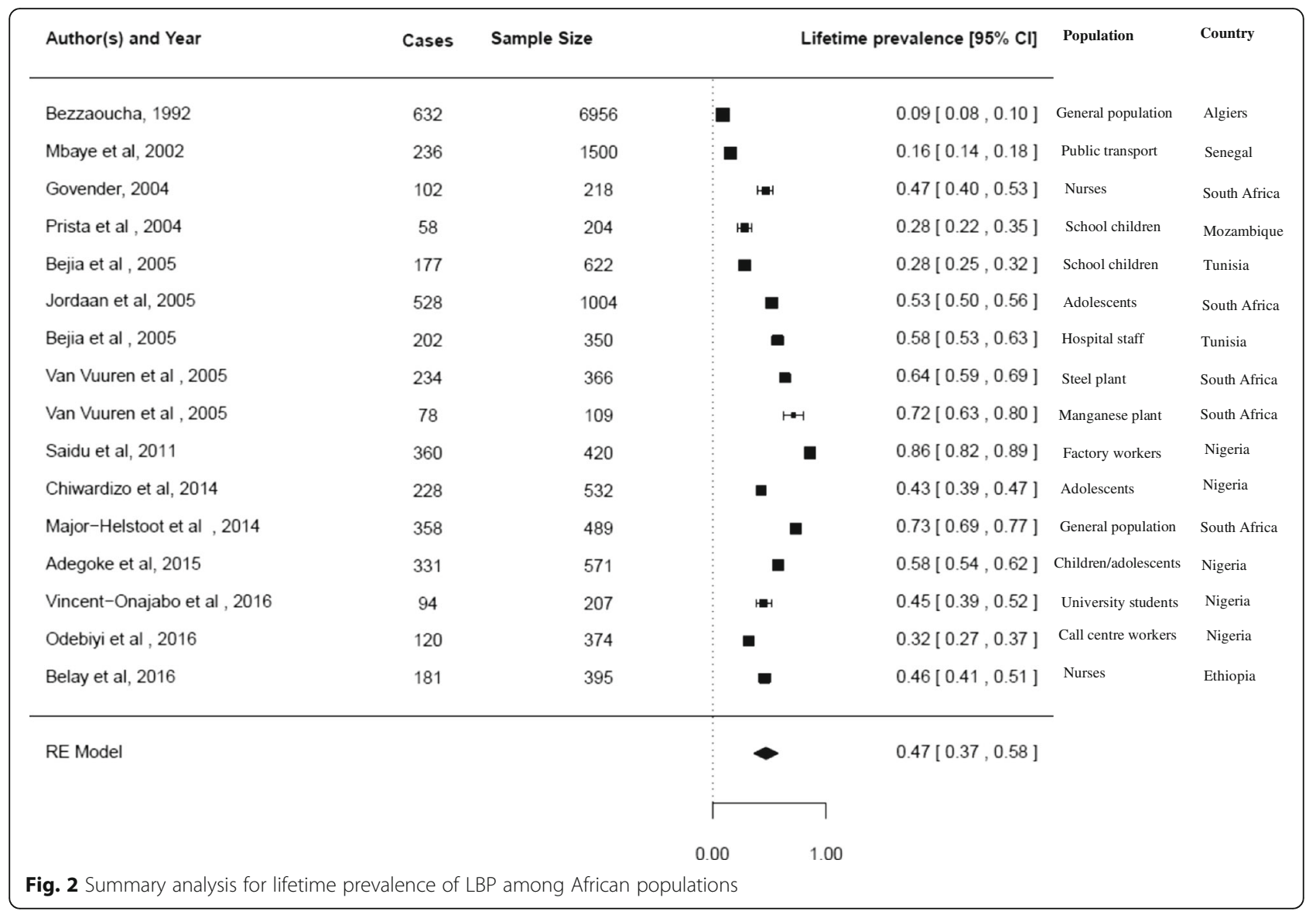

in anticipation of the future economically drain LBP may place on the individual, the industry and the state [53]. Future studies should therefore investigate the factors which lead to the early onset of LBP among African children and adolescents and develop prevention strategies which are effective, feasible and accessible to all people living in rural and urban areas of Africa.
The findings of this review also clearly show a notable difference in point and annual LBP prevalence of close to $20 \%$ between African males and females, with males reporting a higher prevalence. These results indicate a reverse gender pattern compared to global trends which generally indicate that females experience a higher prevalence [92]. What is interesting

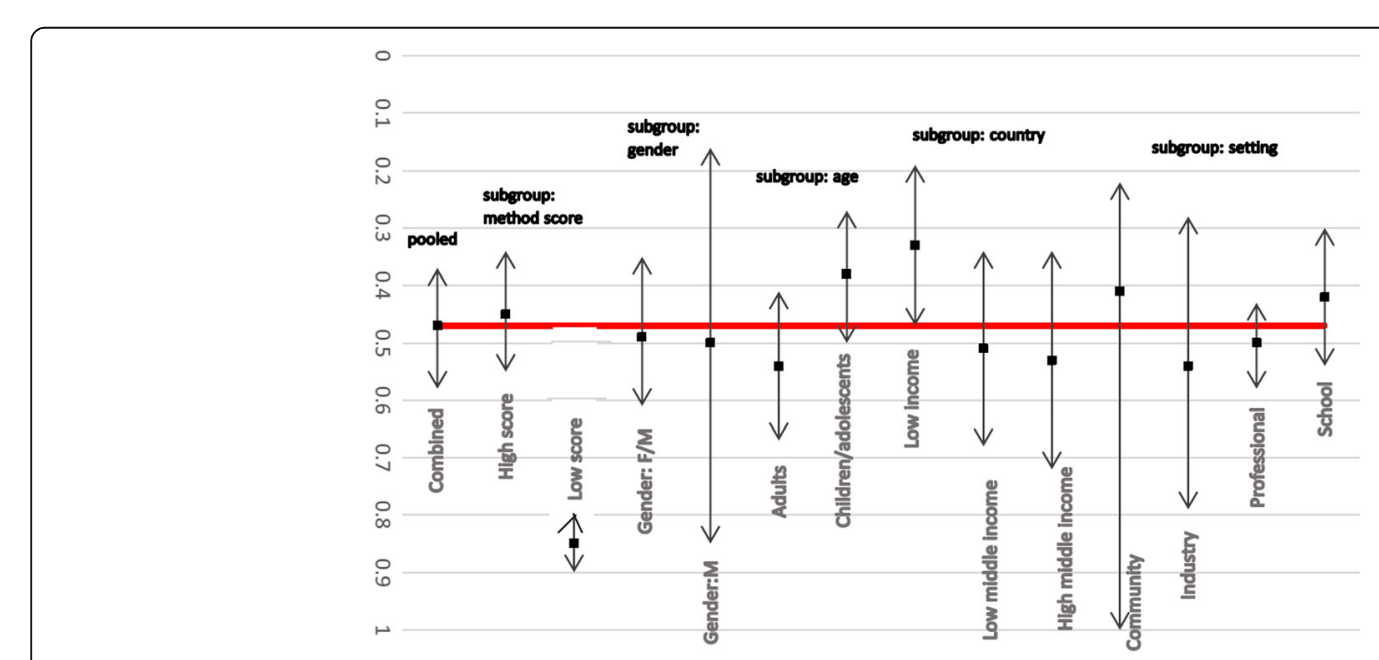

Fig. 3 Subgroup analysis for lifetime prevalence of LBP among African nations (*please note: no subgroup data for Gender:F and Setting:Hospital) 


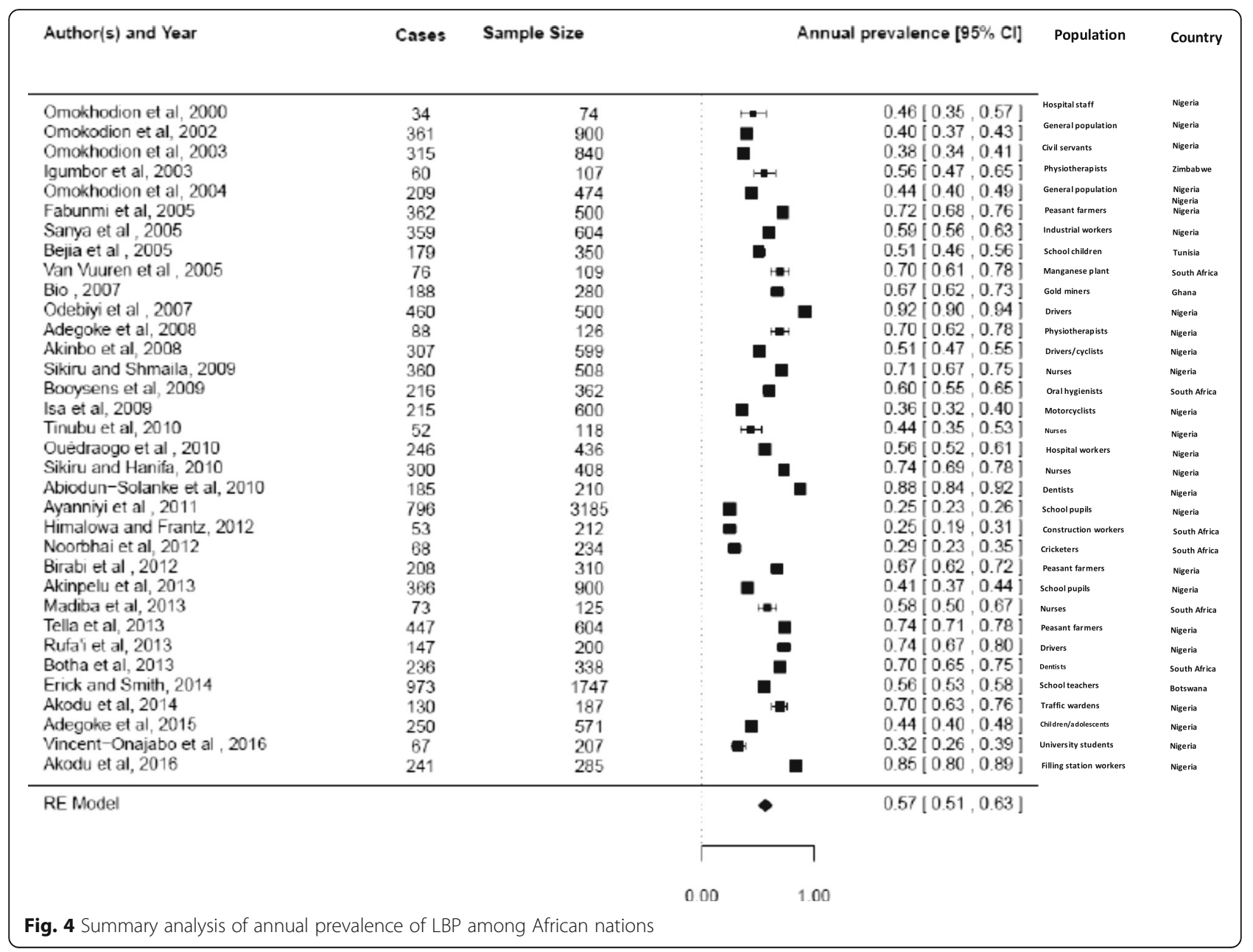

about this finding is that within most African cultures, African males actually tend to under-report health issues as it is perceived to reduce their masculinity [93]. A higher prevalence for African females would therefore have been expected. However, this said, these findings may also be linked to the fact that half of the studies on industry included mostly males or males only, whereas the workers included in the professional subgroup included more females. Since industry-related jobs include more intense physical labour, an over-representation of males may have therefore resulted.

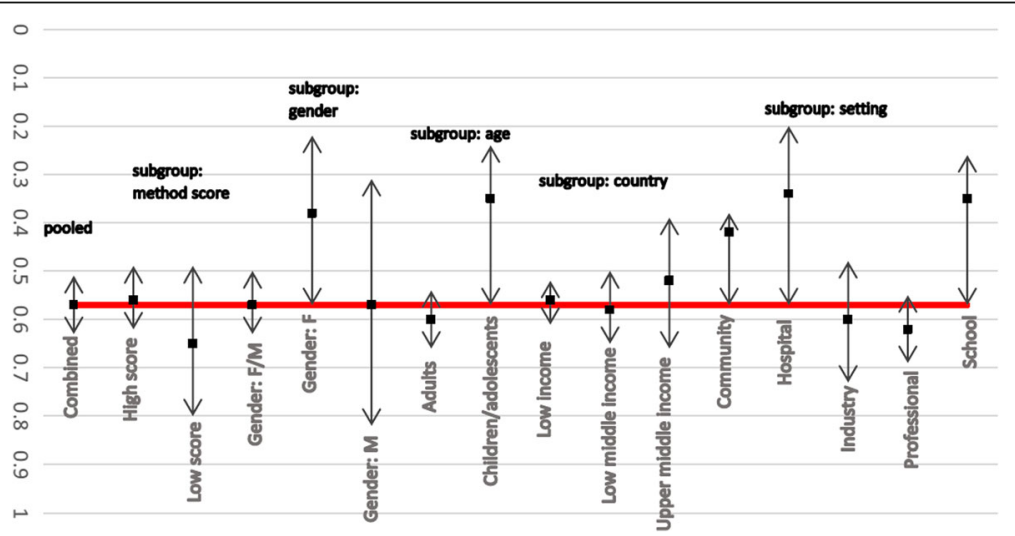

Fig. 5 Subgroup analysis of annual prevalence of LBP among African nations 


\begin{tabular}{|c|c|c|c|c|c|c|}
\hline Author(s) and Year & Cases & Sample Size & Point & prevalence $[95 \% \mathrm{Cl}]$ & Population & country \\
\hline Mulimba, 1990 & 227 & 2201 & घ & $0.10[0.09,0.12]$ & Private patients & Nairobi \\
\hline Harris, 1993 & 68 & 110 & -1 & $0.62[0.53,0.71]$ & Cricketers & South Africa \\
\hline Schierhout, 1993 & 40 & 155 & 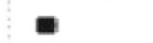 & $0.26[0.19,0.33]$ & Factory workers & South Africa \\
\hline Mijiyawa, 2000 & 3204 & 9065 & घ & $0.35[0.34,0.36]$ & OPD patients & Togo \\
\hline Worku, 2000 & 2340 & 4001 & = & $0.58[0.57,0.60]$ & Mothers & Lesotho \\
\hline Sanya et al , 2005 & 361 & 604 & घ & $0.60[0.56,0.64]$ & Industrial workers & Nigeria \\
\hline Adedoyin et al , 2005 & 770 & 1041 & घ & $0.74[0.71,0.77]$ & Computer users & Nigeria \\
\hline Galukande et al, 2005 & 204 & 1033 & घ & $0.20[0.17,0.22]$ & OPD patients & Uganda \\
\hline Van Vuuren et al , 2005 & 41 & 109 & 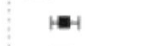 & $0.38[0.29,0.47]$ & Industrial workers & South Africa \\
\hline Ayanniyi et al, 2006 & 763 & 2187 & घ & $0.35[0.33,0.37]$ & Pregnant females & South Africa \\
\hline Hill et al , 2007 & 258 & 1328 & E & $0.19[0.17,0.22]$ & community women & Ghana \\
\hline Naidoo and Coopoo, 2007 & 43 & 107 & $=+$ & $0.40[0.31,0.49]$ & Nurses & South Africa \\
\hline Himalowa and Frantz, 2012 & 146 & 212 & - & $0.69[0.63,0.75]$ & Construction workers & South Africa \\
\hline Desai et al, 2012 & 46 & 76 & $\mapsto-1$ & $0.61[0.50,0.72]$ & General surgeons & South Africa \\
\hline Ogunbode et al , 2013 & 227 & 485 & - & $0.47[0.42,0.51]$ & Adult patients & Nigeria \\
\hline Akinpelu et al, 2013 & 116 & 900 & & $0.13[0.11,0.15]$ & Adolescent students & Nigeria \\
\hline El-Soud et al, 2014 & 119 & 150 & - & $0.79[0.73,0.86]$ & Nurses & Nigeria \\
\hline Chiwardizo et al, 2014 & 49 & 532 & & $0.09[0.07,0.12]$ & Adolescents & zimbabwe \\
\hline Mwaka et al, 2014 & 201 & 532 & = & $0.38[0.34,0.42]$ & Pupils & Uganda \\
\hline Triki et al , 2015 & 882 & 5958 & a & $0.15[0.14,0.16]$ & Children/adolessents & Tunisia \\
\hline Adegoke et al, 2015 & 146 & 571 & a & $0.26[0.22,0.29]$ & Children/adolescents & Nigeria \\
\hline Vincent-Onajabo et al , 2016 & 24 & 207 & & $0.12[0.07,0.16]$ & Call centre workers & Nigeria \\
\hline Belay et al, 2016 & 179 & 395 & a & $0.45[0.40,0.50]$ & Nurses & Egypt \\
\hline RE Model & & & 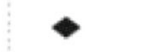 & $0.39[0.30,0.47]$ & & \\
\hline
\end{tabular}

Epidemiologic and methodological challenges in conducting LBP prevalence reviews among African populations

The review process highlighted a number of challenges related to conducting, sourcing and pooling relevant epidemiologic data in Africa. One of the first methodological challenges when conducting such a review, was the uncertainty of whether all relevant data were included in the review. This is because a number of
African research studies may not have been published in journals which are indexed in accessible and commonlyused international databases [73, 74]. Many African LBP studies are published in local journals or as a postgraduate thesis, and not all African universities may have information technology systems which allow online access to their postgraduate theses [74]. Data may therefore only be available in the local university libraries. Furthermore, African LBP researchers may not have the

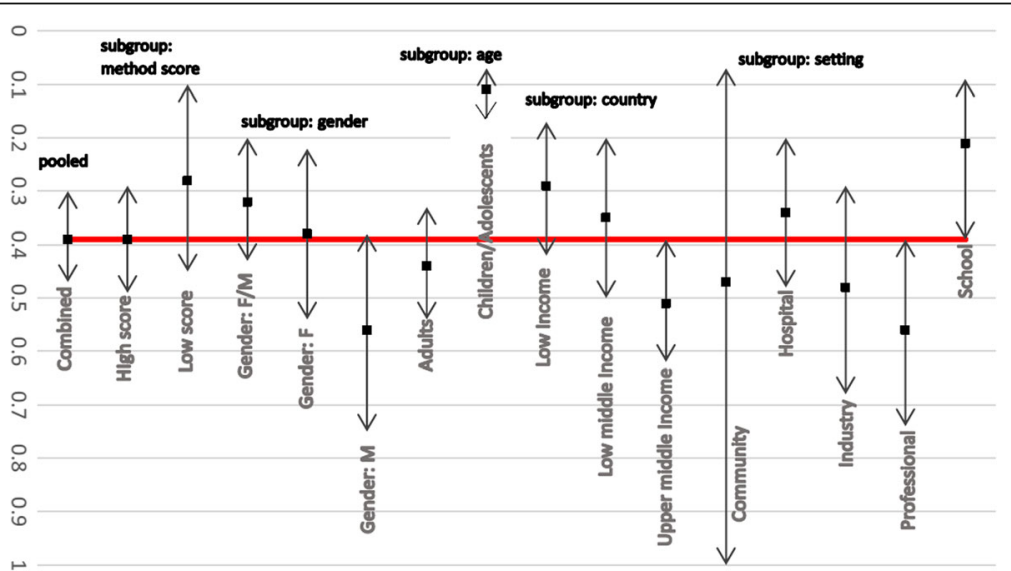

Fig. 7 Subgroup analysis of point prevalence of LBP among African nations 
opportunity to publish in open access journals due to the associated high publication costs [73-75], which leads to difficulty in publishing, as well as accessing and retrieving such publications. The inclusion of all relevant African literature on LBP prevalence can therefore not be guaranteed.

Another challenge in conducting this review is the fact that Africa is riddled by huge economic inequality between countries. We found that most studies were conducted in Nigeria and South Africa, which have the strongest economies in Africa and are currently ranked first and third, respectively in terms of Gross Domestic Product [75]. In these relatively more affluent countries, factors such as economic growth and urbanisation have already followed patterns noted in the developed world and this could have an effect on LBP occurrence and reporting [75]. While research fields such as HIV/AIDS and TB in Africa are well funded by international bodies, this is not the case with LBP research [3]. LBP research in poorer African countries is consequently not possible or encouraged due to prioritisation of research funding towards other pressing health issues. The economic inequality between African countries could therefore have biased our review findings to more affluent countries.

The poor methodological quality of included studies posed another challenge in conducting this review since just over $60 \%$ of the studies could be used in the analyses. Of concern was that most of the shortcomings in the methods reported by the poor quality studies could have been avoided. Similarly, to the previous review [10], and other reviews [2], the poor quality studies in this review generally did not provide a definition of LBP, lacked adequate representation of the population, did not provide response rates or drop-out rates, and neglected to use reliable and/valid instruments (be it a questionnaire, interview, or examination) for collection of data. According to Dionne et al., it is highly recommended that epidemiologic studies should at least provide the case definition used in establishing the prevalence of LBP in a specified population [76]. In addition, this case definition for LBP should be standardized to ensure that greater comparisons between countries (developed or developing) can be made [76, 77], for a greater understanding of LBP to be gained [2]. The validity and reliability of instruments should also be established prior to their administration in a specific population to ensure accurate estimates of prevalence [78]. One important area to address is the development of a valid and reliable LBP measurement instrument which should ideally take context and culture into account. Furthermore, improved collaboration between researchers in different African countries, will facilitate standardization of measuring LBP among Africans to assist with comparisons across countries as well as meta-analytical approaches. It is therefore recommended that future studies prioritize conducting studies with improved methodological quality, provide and use a standardized case definition of LBP, and report essential information, which will lead to accurate assessment, interpretation, translation and comparison of results across studies [79].

Lastly, although measures were taken to ensure that the heterogeneity among studies was considered during metaanalyses, the summary estimates provided in this review should still be viewed with caution [2]. Heterogeneity in observational studies is however expected [76, 77, 79], since populations, and even cultural groups within a specific population, inherently differ [94]. More specifically, heterogeneity of LBP data remains considerable across studies due to the lack of a standardized or universal case definition for LBP [76, 77]. For this reason, the pooling and comparison of LBP data based on different definitions is a challenge on its own, regardless of population and other study characteristic variability [77].

\section{Conclusion}

Since the original review was published in 2007, a number of epidemiologic studies into the prevalence of LBP in Africa have emerged. This review found that the lifetime, annual and point prevalence of LBP among African nations, was higher than the global LBP prevalence reported. Prevention strategies addressing the early onset of LBP among the youth would most likely be the answer to addressing the burden of LBP on future economies in Africa. Caution must however be taken when interpreting the summary estimates provided in this current review, since high heterogeneity, which is expected, was displayed among the included studies. Furthermore, due to the poor methodological quality found among many of the included studies, the over-representation of more affluent African countries and the difficulty in sourcing and retrieving potential African studies, it is recommended that future African LBP researchers conduct methodologically robust studies and report their findings in accessible resources.

\section{Abbreviations}

Cl: Confidence interval; GBD: Global burden of disease; LBP: Low back pain; LMICs: Lower and middle income countries; WHO: World Health

Organization; YLDs: Years lived with disability

\section{Acknowledgements}

The authors would like to acknowledge the staff at the Stellenbosch University Medical and Health Sciences Library for their assistance in retrieving the articles; Prof. Karen Grimmer for assistance in the conceptualization of the idea for the initial review published in 2007 [10], as well as Dr. Faheema Kimmie-Dhansay for assistance in part of the analyses.

Availability of data and materials

Please contact corresponding author for all data.

Authors' contributions

LM: Conceptualization of review update idea and developed the protocol, conducted the update of the search, conducted appraisal of studies, extracted the data, assisted with analyses of the data, wrote the manuscript. 
QL: conceptualization of main review idea, supervised the process, assisted with analyses of the data, contributed to writing the manuscript. KD: independently conducted search, appraisal and extraction of data, assisted with analyses of data, contributed to the writing of the manuscript. BG: conducted the analyses, produced the graphics and contributed to the interpretation and writing of the statistical sections of this manuscript. All authors read and approved the final manuscript.

\section{Ethics approval and consent to participate}

Not applicable.

\section{Competing interests}

The authors declare that they have no competing interest.

\section{Publisher's Note}

Springer Nature remains neutral with regard to jurisdictional claims in published maps and institutional affiliations.

\section{Author details}

'Division of Physiotherapy, Department of Health and Rehabilitation Sciences, Faculty of Medicine and Health Sciences, Stellenbosch University, PO BOX 241, Cape Town 8000, South Africa. ${ }^{2}$ Division of Epidemiology and Biostatistics, Faculty of Medicine and Health Sciences, Stellenbosch University, Tygerberg, South Africa. ${ }^{3}$ Department of Statistics, University of Calcutta, Kolkata, India.

Received: 8 September 2017 Accepted: 4 May 2018

Published online: 21 June 2018

\section{References}

1. Manchikanti L. Epidemiology of low back pain. Pain Physician. 2000;3(2):167-92.

2. Hoy D, Bain C, Williams G, March L, Brooks P, Blyth F, et al. A systematic review of the global prevalence of low back pain. Arthritis Rheum. 2012:64(6):2028-37.

3. Froud R, Patterson S, Eldridge S, Seale C, Pincus T, Rajendran D, et al. A systematic review and meta-synthesis of the impact of low back pain on people's lives. BMC Musculoskelet Disord. 2014;15:50.

4. Hoy D, Smith E, Cross M, Sanchez-Riera L, Buchbinder R, Blyth F, et al. The global burden of musculoskeletal conditions for 2010: estimates from the global burden of disease 2010 study. Ann Rheum Dis. 2014;73:968-74.

5. Hoy D, Brooks P, Blyth F, Buchbinder R. The epidemiology of low back pain. Best Pract Res Clin Rheumatol. 2010;24(6):769-81.

6. Majid K, Truumees E. Epidemiology and natural history of low back pain. Semin Spine Surg. 2008;20:87-92.

7. Woolf AD, Erwin J, March L. The need to address the burden of musculoskeletal conditions. Best Pract Res Clin Rheumatol. 2012;26(2):183-224.

8. March L. The global burden of musculoskeletal conditions - why is it important? Best Pract Res Clin Rheumatol. 2011;24(6):721.

9. Woolf AD, Kristina A. Prevention of musculoskeletal conditions in the developing world. Best Pract Res Clin Rheumatol. 2008;22(4):759-72.

10. Louw QA, Morris LD, Grimmer-Somers K. The prevalence of low back pain in Africa: a systematic review. BMC Musculoskel Disord. 2007:8:105.

11. Hoy D, March L, Brooks P, Woolf A, Blyth F, Vos T, et al. Measuring the global burden of low back pain. Best Pract Res Clin Rheumatol. 2010;24(2): 155-65.

12. Guidelines for reporting of Meta-analysis Of Observational Studies in Epidemiology. https://www.elsevier.com/__data/promis_misc/ISSM_ MOOSE Checklist.pdf. Accessed 11 May 2018.

13. Prospero website. Available: http://www.crd.york.ac.uk/PROSPERO/display_ record.php?ID=CRD42014010417. Accessed May 2018.

14. Ondari-Okemwa E. Scholarly publishing in sub-Saharan Africa in the twenty-first century: challenges and opportunities. First Monday. 2007:12:10.

15. Walker $B$. The prevalence of low back pain: a systematic review of the literature from 1966 to 1998. J Spinal Dis. 2000;13(3):205-17

16. Microsoft Excel. Microsoft 2010 software. Microsoft Corporation Redmond, Washington.

17. Mulimba J. The problems of low back pain in Africa. East Afr Med J. 1990;67(4):250-3.

18. Bezzaoucha A. Descriptive epidemiology of low-back pain in Algiers. Rev Rhum Mal Ostéoartic. 1992;59(2):121-4.
19. Harris I. Prevalence of low back pain in cricketers-an undergraduate epidemiological study. Physiotherapy. 1993:49:65-6.

20. Schierhout G, Myers J, Bridger R. Musculoskeletal pain and workplace ergonomic stressors in manufacturing industry in South Africa. Int J Ind Ergon. 1993;12:3-11.

21. Mijiyawa $\mathrm{M}$, Oniankitan $\mathrm{O}$, Kolani $\mathrm{B}$, Koriko T. Low back pain in hospital outpatients in Lome(Togo). Joint Bone Spine. 2000;67:533-8.

22. Omokhodion F, Umar U, Ogunnowo B. Prevalence of low back pain among staff in a rural hospital in Nigeria. Occup Med. 2000;50:107-10.

23. Worku Z. Prevalence of low back pain in Lesotho mothers. JMPT. 2000;23:147-54

24. Wallner-Schlotfeldt PJ, Stewart A. The predisposing factors to low back pain in workers. SAJP. 2000;56:33-8.

25. Omokodion F. Low back pain in a rural community in south West Nigeria. West Afr J Med. 2002;2:87-90.

26. Mbaye I, Fall M, Wone I, Dione P, Ouattara B, Sow M. Chronic low back pain in a Senegalese pubic transport's company. Dakar Med. 2002;47(2):176-8.

27. Omokodion F, Sanya A. Risk factors for low back pain among office workers in Ibadan, Southwest Nigeria Short report. Occ Med. 2003;53:287-9.

28. I gumbor $E$, Useh U, Madzivire D. An epidemiological study of work-related low back pain among physiotherapists in Zimbabwe. SAJP. 2003;59:7-14.

29. Omokodion F. Low back pain in an urban population in Southwest Nigeria. Trop Dr. 2004;34:17-20.

30. Govender S. Low back pain in the nursing profession-a pilot study. SAOJ. 2004:7-13.

31. Prista A, Balague F, Nordin M, Skovron M. Low back pain in Mozambican adolescents. Eur Spine J. 2004;13:341-5.

32. Fabunmi A, ABa S, Odunaiya N. Prevalence of low back pain among peasant farmers in a rural community in south-West Nigeria. Afr J Med Med Sci. 2005;34(3):259-162.

33. Sanya A, Ogwumike O. Low back pain prevalence amongst industrial workers in the private sector in Oyo state, Nigeria. Afr J Med Med Sci. 2005;34:245-9.

34. Bejia I, Abid N, Salem K, Letaief M, Younes M, Touzi M, et al. Low back pain in a cohort of 622 Tunisian schoolchildren and adolescents: an epidemiological study. Eur Spine J. 2005:14:331-336 (a).

35. Jordaan R, Kruger M, Stewart A, Becker P. The association between low back pain, gender and age in adolescents. SAJP. 2005:61:15-20.

36. Adedoyin R, Idowu B, Adagunodo R, Ooyomi A, Idowu P. Musculoskeletal pain associated with the use of computer systems in Nigeria. Technol Health Care. 2005;13:125-30

37. Bejia I, Younes $M$, Jamila $H$, Khalfallah $T$, Salem $K$, Touzi M, et al. Prevalence and factors associated with low back pain among hospital staff. Joint Bone Spine. 2005;72:254-259 (b).

38. Van Vuuren B, Becker P, Van Heerden H, Zinzen E, Meeusen R. Lower back problems and occupational risk factors in a south African steel industry. Am J Ind Med. 2005:47:45-457.

39. Van Vuuren B, Zinzen E, Van Heerden $H$, Becker $P$, Meeusen R. Psychosocial factors related to lower back problems in a south African manganese industry. J Occup Rehabil. 2005;15:215-25

40. Galukande M, Muwazi S, Mugisa D. Aetiology of low back pain in Mulago hospital, Uganda. Afr Health Sci. 2005;5:164-7.

41. Ayanniyi O, Sanya A, Ogunlade S, Oni-Orisan M. Prevalence and pattern of back pain among pregnant women attending ante-natal clinics in selected health care facilities. Afr J Biomed Res. 2006:9:149-56.

42. Hill A, Darko R, Seffah J, Adanu R, Anarfi J, Duda R. Health of urban Ghanaian women as identified by the Women's health study of Accra. Int J Gynaecol Obstet. 2007;99:150-6.

43. Bio F, Sadhra S, Jackson C, Burge P. Low back pain in underground gold miners in Ghana. Ghana Med J. 2007:41(1):21-5.

44. Balogun M, Owoaje E. Work conditions and health problems of female traders in Ibadan Nigeria. Afr J Med Med Sci. 2007:36(1):57-63.

45. Naidoo R, Coopoo Y. The health and fitness profiles of nurses in KwaZulu-Natal. Curationis. 2007:30(2):66-73.

46. Adegoke B, Akodu A, Oyeyemi A. Work-related musculoskeletal disorders among Nigerian physiotherapists. BMC Musculoskel Disord. 2008:9:112.

47. Akinbo S, Odebiyi D, Osasan A. Characteristics of back pain among commercial drivers and motorcyclists in Lagos, Nigeria. West Afr J Med. 2008:27(2):85-9.

48. Sikiru $L$, Shmaila $H$. Prevalence and risk factors of low back pain among nurses in Africa: Nigerian and Ethiopian specialized hospitals survey study. East Afr J Pub Health. 2009;6(1):22-6.

49. Booyens S, van Wyk P, Postma T. Musculoskeletal disorders amongst practising south African oral hygienists. SADJ. 2009;64(9):400-3. 
50. Tinubu B, Mbada C, Oyeyemi A, Fabunmi A. Work-related musculoskeletal disorders among nurses in Ibadan, south-West Nigeria: a cross-sectional survey. BMC Musculoskel Disord. 2010;11:12.

51. Ouédraogo $D$, Ouédraogo $V$, Ouedraogo $L$, Kinda $M$, Tiéno $H$, Zoungrana $E$, et al. Prevalence and risk factors associated with low back pain among hospital staff in Ouagadougou (Burkina Faso). Med Trop. 2010;70:277-80.

52. Sikiru L, Hanifa S. Prevalence and risk factors of low back pain among nurses in a typical Nigerian hospital. Afr Health Sci. 2010;10(1):26-30.

53. Ayanniyi O, Mbada C, Muolokwu C. Prevalence and profile of back pain in Nigerian adolescents. Med Princ Pract. 2011;20:368-73.

54. Himalowa S, Frantz J. The effect of occupationally-related low back pain on functional activities among male manual workers in a construction company in cape town, South Africa. Occup Healt SA. 2012;18(5):28-32.

55. Desai F, Ellapen $T$, van Heerden $H$. The point prevalence of work-related musculoskeletal pain among general surgeons in KwaZulu-Natal, South Africa. Ergonomics SA. 2012;24(2):18-30.

56. Noorbhai M, Essack F, Thwala S, Ellapen T, van Heerden J. Prevalence of cricket-related musculoskeletal pain among adolescent cricketers in KwaZulu-Natal. SAJSM. 2012;24(1):3-9.

57. Birabi B, Dienye P, Ndukwu G. Prevalence of low back pain among peasant farmers in a rural community in south South Nigeria. Rural Remote Health. 2012;12:1920.

58. Ogunbode A, Adebusoye L, Alonge T, Ogunbode A. Prevalence of low back pain and associated risk factors amongst adult patients presenting to a Nigerian family practice clinic, a hospital-based study. Afr J Prim Health Care. 2012;5(1):1-8.

59. Akinpelu A, Oyewole O, Hammed G, Gbiri C. Prevalence of low back pain among adolescent students in a Nigerian Urban Community. AJPARS. 2013;5(1\&2):29-34

60. Jimoh A, Omokanye L, Salaudeen A, Saidu R, Saka M, Akinwale A. Prevalence of low back pain among pregnant women in Ilorin, Nigeria. Med Pract Rev. 2013;4(4):23-6

61. Madiba S, Hoque M, Rakgase R. Musculoskeletal disorders among nurses in high acuity areas in a tertiary hospital in South Africa. Occup Healt SA. 2013;19(1):20-3.

62. Botha P, Chikte U, Barrie R, Esterhuizen T. Self-reported musculoskeletal pain among dentists in South Africa: a 12-month prevalence study. SADJ. 2014;69(5):208-13.

63. El-Soud A, El-Najjar A, EL-Fattah N and Hassan A. Prevalence of low back pain in working nurses in Zagazig University hospitals: and epidemiological study. Egyptian Rheumatology and Rehabilitation. 2014;41:109-15.

64. Sa'idu I, Utti V, Jaiyesimi A, Rufa'i A, Maduagwu S, Onuwe $H$, et al. Prevalence of musculoskeletal injuries among factory workers in Kano metropolis, Nigeria. Int J Occup Saf Ergon. 2011;17:99-102.

65. Tella B, Akinbo S, Asafa S, Gbiri C. Prevalence and impacts of low back pain among peasant farmers in south-West Nigeria. Int J Occup Med Environ Health. 2013;26:621-7.

66. Rufa'i A, Sa'idu I, Ahmad R, Elmi O, Aliyu S, Jarere A, et al. Prevalence and risk factors for low back pain among professional drivers in Kano. Nigeria: Archives of Environmental and Occupational Health; 2013. [Epub ahead of print].

67. Chiwaridzo M, Naidoo N. Prevalence and associated characteristics of recurrent non-specific low back pain in Zimbabwean adolescents: a cross-sectional study. BMC Musculoskelet Disord. 2014;15:381.

68. Erick P, Smith D. Low back pain among school teachers in Botswana, prevalence and risk factors. BMC Musculoskelet Disord. 2014;15:359.

69. Mwaka E, Munabi I, Buwembo W, Kukkiriza J, Ochieng J. Musculoskeletal pain and school bag use: a cross-sectional study among Ugandan pupils. BMC Research Notes. 2014;7:222.

70. Major-Helstoot M, Crous L, Grimmer-Somers K, Louw Q. Management of LBP at primary care level in South Africa: up to standards? Afr Health Sci. 2014;14:698-706.

71. Mousavi S, Akbari M, Mehdian H, Mobini B, Montazeri A, Akbarnia B, et al. Low back pain in Iran: a growing need to adapt and implement evidence-based practice in developing countries. Spine (Phila Pa 1976). 2011;36(10):E638-46.

72. Calvo-Muñoz I, Gómez-Conesa A, Sánchez-Meca J. Prevalence of low back pain in children and adolescents: a meta-analysis. BMC Pediatr. 2013;13:14.

73. Sawyerr A. African universities and the challenge of research capacity development. JHEA/RESA. 2004;2:211-40.

74. Ngobeni S. Scholarly publishing: the challenges facing the African university press. ASC working paper 1002012.
75. Mutula S. Challenges of doing research in sub-Saharan African universities: digital scholarship opportunities. Inkanyiso: Journal of Humanities and Socia Sciences. 2009;1:1

76. Dionne C, Dunn K, Croft P, Nachemson A, Buchbinder R, Walker B, et al. A consensus approach toward the standardization of back pain definitions for use in prevalence studies. Spine (Phila Pa 1976). 2008;33:95-103.

77. Videman T, Batti MC. Commentary: back pain epidemiology — the challenge of case definition and developing new ideas. Spine. 2012;12:71-2.

78. Stroup D, Berlin J, Morton S, Olkin I, Williamson G, Rennie D, et al. Meta-analysis of observational studies in epidemiology: a proposal for reporting. JAMA. 2000;283(15):2008-12.

79. Beaton D, Bombardier C, Guillemin F, Ferraz M. Guidelines for the process of cross-cultural adaptation of self-report measures. Spine. 2000;25:3186-91.

80. Duval S, Tweedie R. Trim and fill: a simple funnel-plot-based method of testing and adjusting for publication bias in meta-analysis. Biometrics. 2000;56(2):455-63.

81. Isa U, Saminu A, Rufai Y. Prevalence of low back pain complaints among commercial motorcyclists in Kano, Northwest Nigeria. Nigerian Medical Practitioner. 2009;56:19-23.

82. Abiodun-Solanke I, Agbaje J, Ajayi D, Arotiba J. Prevalence of neck and back pain among dentists and dental auxillaries in south western Nigeria. Afr J Med Med Sci. 2010;39:137-42.

83. Oyeyemi A, Rafa'l A, Lawan A. Low back pain incidence, anthropometric characteristics and activities of daily living in pregnant women in a teaching hospital center antenatal clinic. Trop J Obstet Gynaecol. 2013;30:29-37.

84. Triki M, Koubaa A, Masmoudi L, Fellman N, Tabka Z. Prevalence and risk factors of low back pain among undergraduate students of a sports and physical education institute in Tunisia. Libyan J Med. 2015;10:26802.

85. Adegoke B, Odole A, Adeyinka A. Adolescent low back pain among secondary school students in Ibadan, Nigeria. Afr Health Sci. 2015:15:429-37.

86. Vincent-Onabajo G, Nweze E, Kachalla G, Ali M, Usman A, Alhaji M, Umeonwuka C. Prevalence of Low Back Pain among Undergraduate Physiotherapy Students in Nigeria. Pain Res Treat. 2016;123038:4.

87. Odebiyi D, Ogwezi D, Adegoke B. The prevalence of low back pain in commercial motor drivers and private automobile drivers. Nig J Med Rehabil. 2007;21(1 \& 2):21-4.

88. Akodu A, Taiwo A, Jimoh O. Prevalence of low back pain among traffic wardens in Lagos state. Nigeria AJPARS. 2014;6(1 \& 2):37-41.

89. Akodu A, Okafor U, Adebayo A. Prevalence of low back pain among filling stations attendants in Lagos, Southwest Nigeria Afr J Biomed Res. 2016;19: 109-15.

90. Odebiyi D, Akanle O, Akinbo S, Balogun S. Prevalence and impact of workrelated musculoskeletal disorders on job performance of call center operators in Nigeria. Int J Occup Environ Med. 2016;7:98-106.

91. Belay M, Worku A, Gebrie S, Wamisho B. Epidemiology of Low Back Pain among Nurses Working in Public Hospitals of Addis Ababa, Ethiopia East \& Central African Journal of Surgery. 2016:21(1):113-31.

92. Wáng Y, Wáng J, Káplár $X$. Increased low back pain prevalence in females than in males after menopause age: evidences based on synthetic literature review. Quantitative Imaging in Medicine and Surgery. 2016:692:199-206.

93. Thorpe R, Wilson-frederick S, Whitfield K. Health behaviors and all-cause mortality in African-American men. Am J Mens Health. 2013;7(40):8S-18S.

94. Le Gal M, Mainguy Y, Le Lay K, Nadjar A, Allain D, Galissié M. Linguistic validation of six patient-reported outcomes instruments into 12 languages for patients with fibromyalgia. Joint Bone Spine. 2010;77:165-70.

\section{Ready to submit your research? Choose BMC and benefit from:}

- fast, convenient online submission

- thorough peer review by experienced researchers in your field

- rapid publication on acceptance

- support for research data, including large and complex data types

- gold Open Access which fosters wider collaboration and increased citations

- maximum visibility for your research: over $100 \mathrm{M}$ website views per year

At BMC, research is always in progress.

Learn more biomedcentral.com/submissions 